\title{
Changes in carbon density for three old-growth forests on Changbai Mountain, Northeast China: 1981-2010
}

\author{
Li Zhou • Limin Dai • Shaoxian Wang • \\ Xiangtong Huang $\cdot$ Xinchuang Wang $\cdot$ Lin Qi $\cdot$ \\ Qingwei Wang • Guowei Li • Yawei Wei • Guofan Shao
}

Received: 11 November 2010 /Accepted: 18 February 2011 /Published online: 6 July 2011

(C) INRA and Springer Science+Business Media B.V. 2011

\begin{abstract}
- Introduction The old-growth forests on Changbai Mountain have been well protected from human activities and provide a living laboratory for studying forest carbon sequestration under natural environmental conditions.

- Objectives We used data from permanent plots measured periodically in 1981 and 2010 to quantify carbon densities for Korean pine-broadleaf mixed forest, coniferous forest and Erman's birch forest on Changbai Mountain.

- Results Carbon pools were divided into tree stems, leaves, branches, coarse woody debris, tree roots, and soil. Although the mixed forest experienced minor wind damage, every forest component except for coarse woody debris experienced increases in carbon density, and the total forest carbon density increased from 233 to $317 \mathrm{t} \mathrm{Cha}^{-1}$. The coniferous forest was severely damaged by wind, so carbon content in trees decreased but the total forest carbon density still increased from 298 to $327 \mathrm{t} \mathrm{C} \mathrm{ha}^{-1}$. The birch forest gained much carbon in trees but the soil carbon pool remained relatively
\end{abstract}

Handling Editor: Guofan Shao

L. Zhou $(\bowtie) \cdot$ L. Dai $(\bowtie) \cdot$ X. Wang $\cdot$ L. Qi $\cdot$ Q. Wang $\cdot$ G. Li $\cdot$

Y. Wei

Institute of Applied Ecology, Chinese Academy of Sciences,

72 Wenhua Road,

Shenyang 110016, Peoples Republic of China

e-mail: zhouli930@iae.ac.cn

L. Dai

e-mail:1mdai@iae.ac.cn

S. Wang $\cdot$ X. Huang

Changbai Mountain Academy of Sciences,

Erdaobaihe, Antu County 133613, Peoples Republic of China

G. Shao

Department of Forestry and Natural Resources, Purdue University,

West Lafayette, IN 47907, USA stable, and its total carbon density increased from 226 to $281 \mathrm{t} \mathrm{C} \mathrm{ha}^{-1}$. The old-growth forest was more resilient to disturbance than previously thought. The positive increases in carbon for the three old-growth forests suggest that forest landscapes on Changbai Mountain are indeed carbon sinks.

Keywords Carbon sequestration - China forestry.

Long-term observation - Temperate forest . Boreal forest

\section{Introduction}

Carbon budgets and cycling in forest ecosystems associated with human-induced climate change have been important research topics worldwide during the past few decades. Forest ecosystems store $86 \%$ of terrestrial vegetation carbon (Olson et al. 1983) and $73 \%$ of soil carbon on Earth (Post et al. 1982). The average carbon density of forests is about $89 \mathrm{t} \mathrm{C} \mathrm{ha}^{-1}$ (Dixon et al. 1994), much higher than that of grasslands $\left(21 \mathrm{t} \mathrm{C} \mathrm{ha}^{-1}\right)$ and croplands $\left(5 \mathrm{t} \mathrm{C} \mathrm{ha}^{-1}\right)$ (Ajtay et al. 1979). Forest carbon fixation capability is $20-100$ times higher than that of cropland $(\mathrm{Xu}$ and Liu 1992). Therefore, protecting forest ecosystems is an important human action that can play a vital role in offsetting $\mathrm{CO}_{2}$ emissions and mitigating global climate change.

Changbai Mountain in Northeast China is covered with various vegetation types, including Korean pine-broadleaf mixed forest, coniferous forest and Erman birch forest, and also tundra, and is equivalent geographically to extending from the temperate zone to the North Pole. At the same time, there is a large area of old-growth forests that is under strict protection within the Changbai Mountain Nature Reserve (Shao et al. 1996). These forests provide baselines that reveal the potential for continued carbon sequestration in many places where these forests grow (Rhemtulla et al. 
2009). However, the carbon sequestration of Changbai's forests is still quantitatively unclear. It is important to determine if forest carbon sequestration on Changbai Mountain also supports the theory that old-growth forests are carbon sinks found elsewhere on Earth (Luyssaert et al. 2008; Zhou et al. 2006).

Although research on forest structure, function, and productivity on Changbai Mountain was initiated in the early 1980s (e.g., Li et al. 1981), systematic research on forest carbon stock and sequestration did not begin until the 2000s. Earlier studies focused on carbon cycling in individual biomes (e.g., Dai et al. 2002). Zhang et al. (2007) made the first effort to examine the spatiotemporal pattern of ecosystem processes in the Changbai Mountain Nature Reserve by integrating simulation modeling, GIS, remote sensing data, and field-based observations. They found that Changbai's forests as a whole served as a carbon sink and that the broadleaf and Korean pine (Pinus koraiensis) mixed forest displayed the highest net primary production (NPP $1.084 \mathrm{~kg} \mathrm{C} \mathrm{m}^{-2}$ year $^{-1}$ ). Zhu et al. (2010) used 22 forest plots to investigate the altitudinal changes in $\mathrm{C}$ storage in three components (vegetation, detritus, and soil) of three forest ecosystems (broadleaf and Korean pine mixed, coniferous, and Erman birch forests) on Changbai Mountain. They suggested that while $\mathrm{C}$ density of the three ecosystem components showed distinct altitudinal patterns, carbon storage and partitioning among the different components in temperate forests on Changbai Mountain varied greatly with forest type and altitude.

Clearly there are many unknowns and uncertainties regarding forest carbon stocks and their dynamics on Changbai Mountain. The purpose of this study is to shed more light on carbon sequestration for these three forest types based on longterm ground observations on Changbai Mountain. We do so by addressing the basic scientific question: are old-growth forests on Changbai Mountain carbon sinks or carbon sources?

\section{Methods}

\subsection{Study sites}

This study was conducted for three old-growth forests in the Changbai Mountain Biosphere Nature Reserve $\left(41^{\circ} 43^{\prime}-\right.$ $\left.42^{\circ} 26^{\prime} \mathrm{N}, 127^{\circ} 42^{\prime}-128^{\circ} 17^{\prime} \mathrm{E}\right)$, one of the largest nature reserves in China. In 1980, the reserve became affiliated with the World Biosphere Reserve Network under UNESCO's Man and the Biosphere Project, and is known as Changbai Mountain Biosphere Reserve (CBR) (Tang et al. 2010). CBR is characterized by a mountain climate with strong winds in spring and winter. As altitude increases from $442 \mathrm{~m}$ to $2,623 \mathrm{~m}$, the mean annual temperature decreases from $4.9^{\circ} \mathrm{C}$ to $-7.3^{\circ} \mathrm{C}$ and the mean annual precipitation increases from $600 \mathrm{~mm}$ to $1,340 \mathrm{~mm}$ (Zhang et al. 1980). Influenced by the climate gradient, clear altitudinal vegetation zones are formed from the base to the top of Changbai Mountain (Wang et al. 1980). These include: (1) Korean pine-broadleaf mixed forest $(740-1,100 \mathrm{~m})$, dominated by Korean pine (Pinus koraiensis), Amur linden (Tilia amurensis), Manchurian ash (Fraxinus mandshurica) and other broadleaf species; (2) coniferous forest $(1,100$ $1,700 \mathrm{~m}$ ), dominated by Yezo spruce (Picea jezoensis var. komarovii), Korean pine, Manchurian fir (Abies nephrolepis) and Erman's birch (Betula ermanii); and (3) Erman's birch forest (1,700-2,000 m), composed solely of this species.

\subsection{Data sources}

In 1981, 1 ha permanent plots were established in different vegetation zones on the north slope of Changbai Mountain. Every tree $\geq 8 \mathrm{~cm}$ in DBH within the plots was identified and its DBH and height were measured. These original measurements and their derivatives for the Korean pinebroadleaf mixed forest at $740 \mathrm{~m}$, the coniferous forest at 1,620 m, and the Erman's birch forest at 1,990 m were used in this article for computing carbon density in 1981. In 2010, the three permanent plots were re-measured following the same procedure used in 1981.

We measured coarse woody debris (CWD, diameter $\geq$ $2.5 \mathrm{~cm}$, including fallen trees, standing dead trees and stumps) within the plots in 2010. The recorded information includes species $(S)$; DBH for standing dead trees or diameter at large-end and small-end for fallen trees and stumps $(D)$; length for fallen trees and stumps or height for standing dead trees $(L)$; and decay class $(1-5)$ using the classification system reported by Yan et al. (2006) $\left(C_{\mathrm{CWD}}\right)$.

We excavated one soil pit to a depth of $50 \mathrm{~cm}$ in each plot, and took soil samples at five depths $(0-10,10-20,20-30,30$ $40,40-50 \mathrm{~cm}$ ) in the mineral soil (excluding the organic layer) by using a $100-\mathrm{cm}^{3}$ soil sampler. Samples were oven-dried in the laboratory at $105^{\circ} \mathrm{C}$ and weighed to calculate bulk density. Samples were then sub-sampled for measurement of organic matter concentration by wet combustion with $\mathrm{K}_{2} \mathrm{Cr}_{2} \mathrm{O}_{7}$.

\subsection{Carbon computations}

The biomass of all living trees, including above-ground (stems, branches, leaves) and below-ground (roots) were estimated by using allometric species-specific equations (JPFD, 2003; Li et al. 1981; Zhong 2009). Carbon density was then calculated as the product of dry mass and assumed $\mathrm{C}$ concentration of $50 \%$.

CWD density and carbon content for different decay classes and different species have been measured in previous research (Zhou 2007). Carbon density of CWD for each forest type in 2010 was calculated by species and 
decay class. We obtained CWD biomass for the three forest types in 1981 from Liu and Wang (1992), Dai et al. (2000) and Yang et al. (2002). CWD carbon density in 1981 was also calculated as the product of dry mass and assumed C concentration of $50 \%$.

We calculated the soil organic carbon densities for the three forest types in 2010 using the following equation:

$D=\sum_{i=1}^{n} 0.58 \times T_{i} \times B_{i} \times O_{i}$

where $D$ is soil organic carbon density $\left(\mathrm{t} \mathrm{Cha}^{-1}\right) ; n$ is the number of soil layers; 0.58 is the Bemmelen index that converts organic matter concentration to organic $\mathrm{C}$ concentration; and $D_{\mathrm{i}}, B_{\mathrm{i}}$ and $M_{\mathrm{i}}$ are thickness $(\mathrm{cm})$, bulk density (g $100 \mathrm{~cm}^{-3}$ ) and organic matter concentration in soil layer $i$, respectively.

We calculated the soil carbon densities for the three forest types by referring to published data from Cheng et al. (1981) and Pei et al. (1981). We obtained soil carbon density for each forest type in 1981 based on soil organic matter, soil bulk density and soil thickness $(50 \mathrm{~cm}$, the same as in 2010). The above equation was then used to calculate carbon densities in the three forests.

Carbon content from forest floor vegetation was not included in this study, since it accounts for only a small fraction $(<2 \%)$ of total forest carbon storage and is relatively stable over time.

\section{Results}

\subsection{Korean pine-broadleaf mixed forest}

The total carbon density of Korean pine-broadleaf mixed forest was $233 \mathrm{t} \mathrm{C} \mathrm{ha}^{-1}$ in 1981 and $317 \mathrm{t} \mathrm{C} \mathrm{ha}^{-1}$ in 2010, representing an increase of $84 \mathrm{t} \mathrm{Cha}^{-1}$ or $36.1 \%$ during the past three decades (Table 1). Carbon density in almost all

Table 1 Changes in carbon density $\left(\mathrm{t} \mathrm{C} \mathrm{ha}^{-1}\right)$ between 1981 and 2010 for Korean pine-broadleaf mixed forest on Changbai Mountain

\begin{tabular}{llll}
\hline & Component & 1981 & 2010 \\
\hline Above-ground & Stems & 93.3 & 127 \\
& Leaves & 2.85 & 3.89 \\
& Branches & 12.4 & 16.9 \\
& Coarse woody debris & 8.13 & 7.53 \\
Sub-total & & 117 & 156 \\
Below-ground & Roots & 25.5 & 34.8 \\
& Soil & 90.8 & 126 \\
Sub-total & & 116 & 161 \\
Total & & 233 & 317 \\
\hline
\end{tabular}

the components increased consistently except for that in CWD, which decreased slightly from 8.13 to $7.53 \mathrm{t} \mathrm{C} \mathrm{ha}^{-1}$ from 1981 to 2010 . The increase in carbon density below ground (38.6\%) exceeded that for above ground (33.5\%).

Above ground carbon density was nearly the same as that below ground in 1981, but was higher than the latter in 2010 . Tree stems contained the most carbon among above-ground components, followed by branches or CWD, depending on the year. Carbon density in soil was over three times higher than that in tree roots, and even exceeded that in tree stems in 2010 .

\subsection{Coniferous forest}

The total carbon density of the coniferous forest was $298 \mathrm{t} \mathrm{C} \mathrm{ha}^{-1}$ in 1981 and $327 \mathrm{t} \mathrm{C} \mathrm{ha}^{-1}$ in 2010, representing an increase of $29 \mathrm{t} \mathrm{C} \mathrm{ha}^{-1}$ or $9.74 \%$ during the past three decades (Table 2). Carbon density in all living tree components decreased, but that in CWD doubled (from 26.7 to $55.1 \mathrm{t} \mathrm{C} \mathrm{ha}^{-1}$ ). Carbon density in soil increased from 124 to $148 \mathrm{t} \mathrm{C} \mathrm{ha}^{-1}$ or by $19.9 \%$ between 1981 and 2010. The decreases in carbon density in living tree components were consistent, ranging from $15 \%$ to $18 \%$.

In 1981, above-ground carbon density was nearly the same as below-ground density, while it was slightly lower than the latter in 2010. Tree stems contained the most carbon among above-ground components throughout this period. Carbon density in soil was almost 5-8 times higher than that in tree roots, and even exceeded that in tree stems. Carbon density in soil was the highest among all the forest components.

\subsection{Erman's birch forest}

The total carbon density of the birch forest was $226 \mathrm{t} \mathrm{C} \mathrm{ha}^{-1}$ in 1981 and $281 \mathrm{t} \mathrm{C} \mathrm{ha}^{-1}$ in 2010 , representing an increase of $55 \mathrm{t} \mathrm{C} \mathrm{ha}^{-1}$ or $24.3 \%$ during the past three decades (Table 3). Carbon density in all the above-ground components increased by $72.4 \%$. Although soil carbon

Table 2 Changes in carbon density $\left(\mathrm{t} \mathrm{C} \mathrm{ha}^{-1}\right)$ between 1981 and 2010 for coniferous forest on Changbai Mountain

\begin{tabular}{llll}
\hline & Component & 1981 & 2010 \\
\hline Above-ground & Stems & 105 & 88.1 \\
& Leaves & 5.70 & 4.67 \\
& Branches & 15.3 & 12.8 \\
& Coarse woody debris & 26.7 & 55.1 \\
Sub-total & & 152 & 160 \\
Below-ground & Roots & 22.3 & 18.9 \\
& Soil & 124 & 148 \\
Sub-total & & 146 & 167 \\
Total & & 298 & 327 \\
\hline
\end{tabular}


Table 3 Changes in carbon density ( $\mathrm{t} \mathrm{Cha}^{-1}$ ) between 1981 and 2010 for Erman's birch forest on Changbai Mountain

\begin{tabular}{llll}
\hline & Component & 1981 & 2010 \\
\hline Aboveground & Stems & 47.7 & 80.3 \\
& Leaves & 0.95 & 1.61 \\
& Branches & 5.73 & 9.63 \\
& Coarse woody debris & 1.72 & 5.25 \\
Sub-total & & 56.1 & 96.7 \\
Belowground & Roots & 14.3 & 24.1 \\
& Soil & 156 & 160 \\
Sub-total & & 170 & 184 \\
Total & & 226 & 281 \\
\hline
\end{tabular}

density was nearly static between 1981 and 2010, carbon in roots increased by $68.2 \%$. Below-ground carbon density increased by $8.36 \%$.

Although above-ground carbon density was much lower than below-ground density, the gap narrowed over time. The majority of above-ground carbon was stored in tree stems. Carbon density in soil was the highest among all the forest components.

\subsection{A comparison among three forest types}

In both 1981 and 2010, the coniferous forest had the highest carbon density, followed by the mixed forest and birch forest. All three forests experienced increases in above-ground, below-ground and total carbon densities, with the exception of tree components of the coniferous forest. For the mixed forest, the increase in carbon density resulted simultaneously from growth of above-ground living tree components and carbon accumulation in the soil (Table 1). For the coniferous forest, this increase resulted primarily from carbon accumulation in CWD and the soil (Table 2); while for the birch forest, this increase resulted only from the the growth of living tree components (Table 3). Since soil was the largest carbon pool, especially for the coniferous and birch forests, changes in soil carbon density had a major influence on the total below-ground carbon density in those three forests (Tables 1-3). This suggests that carbon density in living trees is higher at lower elevations, whereas that of soil carbon density is greater at higher elevations.

\section{Discussion}

\subsection{Implications}

From 1981 to 2010, the mixed, coniferous and birch forests on Changbai Mountain experienced increases in above-ground, below-ground and total carbon densities. During this time, the total carbon densities of the three old-growth forests increased by 84,29 , and $55 \mathrm{t} \mathrm{Cha}^{-1}$, respectively. These results confirm that the forests have acted as a carbon sink during the past three decades, having sequestrated 2.79, 0.97 and $1.83 \mathrm{tC}$ $\mathrm{ha}^{-1}$ year ${ }^{-1}$, respectively. These numbers are higher than those reported for other old-growth forests (Harmon et al. 2004; Luyssaert et al. 2008).

We also found that the above-below ground carbon ratio varied among the three forest types. The aboveground components contributed about $47 \%, 27 \%$ and $74 \%$ of the carbon sink in the mixed, conifer and birch forests, respectively; while $53 \%, 73 \%$ and $26 \%$ of the carbon sink was contributed by belowground components (mainly soil organic carbon) during the past three decades (Fig. 1).

Carbon density in all the components of the mixed forest increased consistently from 1981 to 2010, suggesting that this forest type is a stable carbon sink. Because the mixed forest is the most extensive type in the greater Changbai Mountain area, the entire forest landscape is likely a carbon sink (Zhang et al. 2007). This is even more likely due to China's Natural Forest Conservation Program (Zhang et al. 2000), which has banned logging from many forests on Changbai Mountain since 1998. Because the mixed forest plot was located inside the Changbai Mountain Nature Reserve, where human disturbance is limited, the increase in carbon density in the mixed forest suggests that the existing climatic conditions have been favorable to the growth of this forest during the past three decades.

A decrease in living tree carbon density $\left(16.9 \mathrm{tC} \mathrm{ha}^{-1}\right)$ and an increase in CWD carbon density $\left(28.4 \mathrm{tC} \mathrm{ha}^{-1}\right)$ in the coniferous forest suggest that wind disturbances have occurred in this forest between 1981 and 2010. Forest gaps were formed and, as a result, forest floors should receive more solar radiation, which could result in higher soil

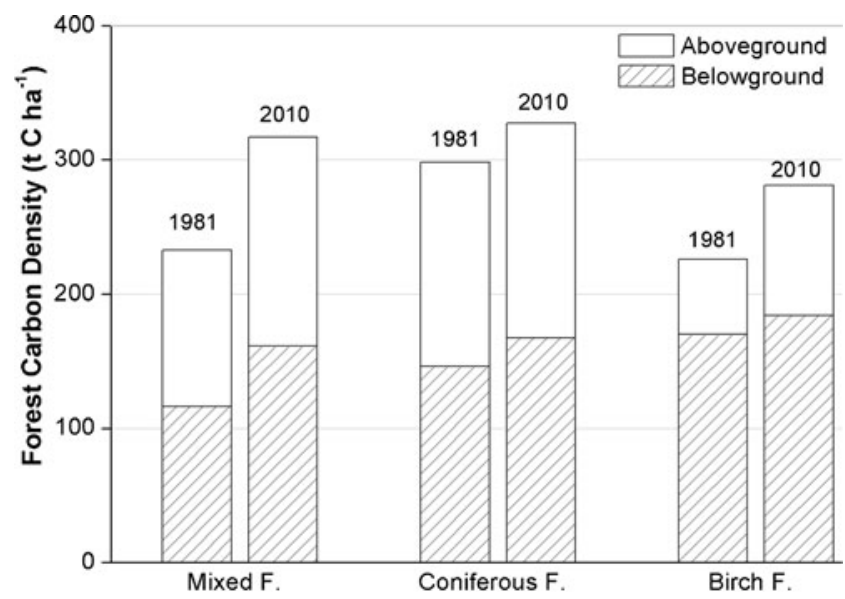

Fig. 1 A comparison of the carbon densities for three forest types on Changbai Mountain 
temperature for the coniferous forest. However, the wind disturbances did not seem to damage the soil carbon pool despite the fact that the stability of that pool in the boreal forest is sensitive to temperature increases (Goulden et al. 1998). The soil organic carbon in the coniferous forest increased by $24 \mathrm{tC} \mathrm{ha}^{-1}$ during the three decades and contributed about $0.8 \mathrm{tC} \mathrm{ha}^{-1}$ year $^{-1}$ to the carbon sink. This result was consistent with those reported by Zhou et al. (2006) for subtropical evergreen old-growth forests. It is possible that extremely low temperatures and high winds led to a decrease in the decomposition rate of litter and CWD and an increase in organic carbon storage over time. It should be noted, however, that, despite the wind damage, the coniferous forest was still a carbon sink, thereby further enhancing the likelihood that forests on Changbai Mountain are a carbon sink. In effect, the old-growth forest appears to be more resilient to disturbance than we initially anticipated (Goulden et al. 1998).

The birch forest is composed almost entirely of Erman's birch, reflecting the fact that this tree species can tolerate a windy and cold environment. A sharp increase in living tree carbon density may be driven by increased temperature, although forest mortality increased as indicated by a threefold increase in CWD. Wind disturbances between 1981 and 2010 may have exceeded the tolerance of Erman's birch.

\subsection{Certainty vs uncertainty}

The estimates of carbon density for living trees and changes in this density over time are relatively reliable because: (1) the three permanent forest plots were selected because they were representative of typical forest types on Changbai Mountain (Dai et al. 2011); (2) carbon contents in living trees were computed by using species-specific biomass equations developed from trees sampled in nearby forests; and (3) repeated measurements over time were used to quantify changes in forest biomass and carbon. Because a single 1-ha plot was used for each forest type, we were unable to compute the precision of carbon density estimates.

Carbon contents in CWD increased in the three forests, particularly in the coniferous forest. Major wind throw started to occur in the mid-1980s (Shao et al. 1996) and has caused continuous damage to forests on Changbai Mountain since then (Tang et al. 2010). Trees at higher elevations experienced the most damage and spruce/fir trees were more vulnerable than birch to strong winds in winter. This is why there were many more dead trees in the coniferous forest than in others.

There was great variation in soil carbon density on Changbai Mountain, especially in the mixed and coniferous forests. It is worth noting that the measurements of soil carbon densities in 1981for the three forest types did not take changes of bulk density with depth of soil into account although it was known that bulk density typically increases with soil depth (Wu et al. 2004). But the data we used were consistent over time. Therefore, we have reasonable confidence about the changes in soil carbon density over time for each forest.

In this research we did not calculate carbon accumulation in litter and organic layers. Past studies suggest that the carbon storage in litter is relatively small and stable in general, accounting for only $1-4 \%$ of the total forest carbon storage (Fang et al. 2002; Zhong 2009; Zhu et al. 2010).

\section{Conclusions}

The mixed, coniferous and birch forests, representing those from low to high elevations on Changbai Mountain, experienced different carbon processes over the period from 1981 to 2010. The mixed forest at a lower elevation was not faced with as much wind damage as were the two higher-elevation forests. The relatively favorable environment at lower elevations aided carbon accumulation in every component of the mixed forest. In contrast, windthrow increased forest mortality and created canopy gaps in coniferous and birch forests. The natural disturbances did not damage the soil carbon pool in either of these forests. Total forest carbon densities for the coniferous and birch forests also increased from 1981 to 2010 . The positive increases in carbon densities in the three forests indicate that the old-growth forest is more resilient to disturbance than previously thought, and that the forest landscape on Changbai Mountain is indeed a carbon sink. Our finding at the local scale is consistent with the suggestion of Luyssaert et al. (2008) and Zhou et al. (2006) that old-growth forests can continue to accumulate carbon. Should increased wind disturbances be one consequence of underlying global climate change, then the forest carbon dynamics of oldgrowth forests have indeed been altered but not destroyed by the changing climate.

Acknowledgments This research was supported financially by the National Natural Science Foundation of China (30800139 \& 40873067) and The International Partnership Program for Innovation Team and the Visiting Professorship for Senior International Scientists of the Chinese Academy of Sciences. We would like to thank Brett Martin for his further editing of our manuscript. We would also thank the two anonymous reviewers who provided constructive comments for improving the manuscript.

\section{References}

Ajtay GL, Ketner P, Duvigneaud P (1979) Terrestrial primary production and biomass. In: Bolin B, Degens T, Kempe S, Ketner P (eds) The global carbon cycle. Scope 13. Wiley, Chichester, pp 129-181 
Cheng BR, Xu GS, Ding GF and Zhang YH (1981) The main soil groups and their properties of the nature reserve on northern slope of Changbai Mountain (in Chinese). Res For Ecosyst 2: 196-206

Dai LM, Xu ZB, Chen H (2000) Storage dynamics of fallen trees in the broad- leaved and Korean pine mixed forest (in Chinese). Acta Ecol Sin 20:412-416

Dai LM, Wu G, Zhao JZ, Kong HM, Shao GF, Deng HB (2002) Carbon cycling of alpine tundra ecosystems on Changbai Mountain and its comparison with arctic tundra. Sci China Ser D-Earth Sci 45:903-910

Dai LM, Qi L, Su DK, Wang QW, Ye YJ and Wang Y (2011) Changes in forest structure and composition on Changbai Mountain in Northeast China. Ann For Sci. doi:10.1007/s13595-011-0095-x

Dixon RK, Solomon AM, Brown S, Houghton RA, Trexier MC, Wisniewski J (1994) Carbon pools and flux of global forest ecosystems. Science 263:185-190

Fang YT, Mo JM, Huang ZL et al (2002) Carbon sccumulation and distribution in Pinus massoniana and Schima superb mixed forest ecosystem in Dinghushan Biospherereserve (in Chinese). J Tropical Subtropical Bot 11:47-52

Goulden ML, Wofsy SC, Harden JW, Trumbore SE, Crill PM, Gower ST, Fries T, Daube BC, Fan S-M, Sutton DJ, Bazzaz A, Munger JW (1998) Sensitivity of boreal forest carbon balance to soil thaw. Science 279:214-217

Harmon ME, Bible K, Ryan MJ, Shaw DC, Chen H, Klopatek J, Li X (2004) Production, respiration and overall carbon balance in an old-growth Pseudotsuga/Tsuga forest ecosystem. Ecosystems 7:498-512

Jilin Province Forestry Department (JPFD) (2003) One single tree volume equations of Jilin Province (in Chinese). Changchun: Jilin Province Forestry Department

Li WH, Deng MK, Li F (1981) Study on biomass and primary production of main ecosystems in Changbai Mountain (in Chinese). Res For Ecosyst 2:34-50

Liu QJ, Wang Z (1992) Fallen trees and their relationship with the regeneration of Betula Ermanii forest in Changbai Mountain (in Chinese). Res For Ecosyst 6:63-67

Luyssaert S, Schulze ED, Borner A, Knohl A, Hessenmoller D, Law BE, Ciais P, Grace J (2008) Old-growth forests as global carbon sinks. Nature 455:213-215

Olson JS, Watts JA, and Allison LJ (1983) Carbon in live vegetation of major world ecosystems. Report ORNL-5862, Oak Ridge National Laboratory, Oak Ridge, TN

Pei TF, Sun JZ, Lu FY, Chi ZW, Li WX (1981) The main soil groups and their properties of the nature reserve on northern slope of Changbai Mountain. Res For Ecosyst 2:187-195
Post WM, Emanuel WR, Zinke PJ, Stangenberger AG (1982) Soil carbon pools and world life zones. Nature 298:156-159

Rhemtulla JM, Mladenoff DJ, Clayton MK (2009) Historical forest baselines reveal potential for continued carbon sequestration. Proc Natl Acad Sci USA 106:6082-6087

Shao GF, Zhao G, Zhao SD, Shugart HH, Wang SX, Schaller J (1996) Forest cover types derived from Landsat TM imagery for Changbai Mountain Area of China. Can J For Res 26:206-216

Tang LN, Shao GF, Piao ZJ, Dai LM, Jenkins MA, Wang SX, Wu G, Wu JG, Zhao JZ (2010) Forest degradation deepens around and within protected areas in East Asia. Biol Conserv 143:1295-1298

Wang Z, Xu Z, Tan Z, Dai H, Li X (1980) The main forest types and their features of community structure in northern slope of Changbai Mountain (in Chinese). Res For Ecosyst 1:25-42

Wu JG, Zhang XQ, Xu DY (2004) Impact of land use change on soil storage (in Chinese). Chin J Appl Ecol 15:593-599

Xu DY, Liu SR (1992) Greenhoues effect, global warming and forestry (in Chinese). World For Res 5:25-28

Yan ER, Wang XH, Huang JJ (2006) Cconcept and classification of coarse woody debris in forest ecosystems (in Chinese). Front Biol China 1:76-84

Yang LY, Dai LM, Zhang YJ (2002) Storage and decomposition of fallen wood in dark coniferous forest on the North Slope of Changbai Mountain (in Chinese). Chin J Appl Ecol 13:1069-1071

Zhang FS, Chi ZW, Li XY (1980) The primary analysis and evaluation on climate in Changbai Mountain (in Chinese). Res For Ecosyst $1: 193-213$

Zhang PC, Shao GF, Zhao G, LeMaster DC, Parker GR, Dunning JB, Li QL (2000) Ecology: China's forest policy for the 21st century. Science 288:2135-2136

Zhang N, Yu ZL, Yu GR, Wu JG (2007) Scaling up ecosystem productivity from patch to landscape: a case study of Changbai Mountain Nature Reserve, China. Landsc Ecol 22:303-315

Zhong L (2009) The response of ecosystem carbon density to harvesting disturbance in broadleaved-Korean pine mixed forest in Changbai Mountain (in Chinese). DS thesis, Graduate University of Chinese Academy of Sciences, Beijing

Zhou L (2007) Ecological study on woody debris in broadleaved Korean pine forest in Changbai Mountain (in Chinese), DS thesis, Graduate University of Chinese Academy of Sciences, Beijing

Zhou GY, Liu SG, Li ZA, Zhang DQ, Tang XL, Zhou CY, Yan JH, Mo JM (2006) Old-growth forests can accumulate carbon in soils. Science 314:1417

Zhu BA, Wang XP, Fang JY, Piao SL, Shen HH, Zhao SQ, Peng CH (2010) Altitudinal changes in carbon storage of temperate forests on Mt.Changbai, Northeast China. J Plant Res 123:439-452 